\title{
Modality matters: On social forces determining what is standard in German Sign Language (DGS)
}

\author{
Hanna Jaeger (Leipzig)
}

\begin{abstract}
Focusing on the social situation of German Sign Language (DGS) and their users, the article explores to what extent Ammon's model of social forces that determine what is standard in language can also be applied to visual spatial languages. The paper demonstrates that Ammon's model is implicitly modality bound and as such cannot fully account for the situation of DGS-using community which largely consists of L2-signers. Although an alternative model is not explicitly offered, the author shows that the model of social forces will need to be extended in order to be modality independent, i.e. applicable to both spoken and signed languages and their communities.
\end{abstract}

\section{Introduction}

It has long been claimed that sign linguistic research will contribute to a more thorough and holistic understanding of language as human faculty (Siple 1978). Yet on the whole, sign languages, or more precisely, scholarly findings in relation to visual spatial languages, are rather under-represented in wider sociolinguistic discourses (e. g. Holmes 2013; Wardhaugh 2011). As a somewhat 'exotic' language type they may increasingly attract attention (e.g. Woll/Sutton-Spence 2004) but on the whole, hey are a far cry from being awarded the same amount of differentiated attention afforded to other languages. Even after more than half a century of academic analysis of visual spatial languages, the impact of sign linguistic research in terms of knowledge generation within the academic domain of sociolinguistics remains to be determined.

Although seldom overtly acknowledged, much sociolinguistic theorising is intrinsically modality-bound, i. e. based on knowledge generated in the context of spoken (and/or written) language research. Given the fact that for the vast majority of people in this world everyday social interaction is negotiated via oral-aural communication, this might be perceived as a reflection of everyday human interaction. At the same time, however, this widespread perspective clearly embodies a bias in the study of natural languages towards aural-oral languages, which is seldom explicitly acknowledged (or possibly even recognised?), let alone overtly challenged. The prevalent spoken language bias constrains the sociolinguistic knowledge base in the sense that the focus on language-based interaction in spoken language communities inhibits language modality-independent theorising. At the same time, exploring 
sociolinguistic forces and processes that operate within sign language communities, which communicate predominantly via the visual-spatial modality, facilitates a more holistic understanding of language as human faculty.

The following paper will both identify some of the problems in relation to the issue of implicit modality-boundedness in the sociolinguistic domain, and explore potential contributions to the field that can be derived from considering social forces at play within sign language communities. As a case in point, I will consider Ammon's model of the Social Power Field (Ammon 2003, 2005), which the author developed and proposed in order to account for social forces that determine what is standard in German. I will demonstrate that this model is explicitly language-related and implicitly modality-bound, which restricts its explanatory power when it comes to accounting for respective sociolinguistic dynamics in the German sign language community.

\section{Three preliminary remarks}

First of all, and before considering it in more detail, it must be acknowledged that Ammon (2003: 1) never claimed that his model was universally applicable. In fact, in his preliminary remarks he argues that the model he offered "proved reasonably adequate" for describing and explaining the situation in "various German-speaking countries, especially Germany, Austria and German-speaking Switzerland" (ibid.). However, whilst he suggests that it "would probably be more generally applicable, beyond the German example and beyond plurinational languages" (ibid.), the author overtly invites other scholars to critically engage with his model by offering alternative approaches or contributing additional viewpoints. In this paper I will accept this invitation and challenge Ammon's model by examining its explanatory force in terms of accounting for social powers at play when it comes to determining "what is standard" (ibid.) in a visual-spatial language, Deutsche Gebärdensprache (DGS, German Sign Language).

Secondly, whilst he considers social forces that play a key role in the context, throughout his paper, Ammon remains notably vague when it comes to outlining his understanding of "what is standard" in the first place. He neither offers any precise definition, nor does he clearly delineate between concepts such as "standard" and "norm", nor does he overtly discuss aspects of mediality by differentiating between spoken and written representations of what is standard in a language.

At first sight, this poses a challenge for any critical engagement with the author's position, as one is left with some uncertainty as to whether one's own definitions are in line with Ammon's understanding of the respective concepts. One might even want to argue that in some sense it is difficult to evaluate at all the appropriateness of a model that its author might be ambiguous about. Notwithstanding the frustration this might cause for the readership, I presume that this approach is to be interpreted as a strategic choice rather than an oversight. Whilst it would be nice (and academically pleasing) to be offered a concise definition of "what is standard", the lack of definition does not really impede on his identification of a set of social forces that play a role in relation to the wider subject matter of language standardisation. For the purposes of this paper I define "standard" as a supra-regional language variety, which carries a certain prestige and which is recognised as "standard" by 
the language community. Due to its circularity, this definition, one might wish to put forward, is just as vague as Ammon's treatment of the subject matter. A detailed treatment of questions concerning standard sign language and sign language standardisation I refer to Eichmann $(2009,2013)$, in the ensuing paper I wish to focus my attention on the question to what extent the proposed model of social forces captures relevant dynamics in the DGS community.

Thirdly, Ammon never claimed to offer a model that was modality-neutral. In fact, whilst his model is deeply modality-bound, he does not even mention the issue of modality at all. This, it will be argued, demonstrates the spoken/written language bias in sociolinguistic theorising, a practice this paper proposes to critically challenge.

\section{On the linguistic situation of DGS}

Prior to considering the application of Ammon's model to the situation of DGS, let me briefly outline the field of tension sociolinguists dealing with sig languages are faced with. First of all, just as any other natural language, DGS varies regionally, socially and situationally across Germany. Variation is widely accepted as part and parcel of DGS and clearly recognised both by native signers and L2 learners. However, whilst other sign languages have attracted much scholarly attention in this regard (e. g. Lucas/Bayley 2005; Bayley/Lucas 2007; Lucas et al. 2002; Schembri et al. 2009), to date there is rather little systematic research into this area in relation to DGS (e. g. Langer 2012; Hillenmeyer/Tilmann 2012).

Another characteristic which DGS users and scholars are confronted with, is the absence of a recognised codified variety, which is often understood by DGS learners and users as the same as "not having a standard variety" at all. In other words, being confronted with variety across the sociolinguistically relevant spectrum (geography, time, situation, person), both L1 signers and L2 learners alike, often presume the non-existence of a "standard variety", because there is no reference body (e. g. DVD, CD-ROM, website etc.) that would be recognised and referred to as codifying a supra-regional variety. Although it is well reasonable to argue that a standard variety might not necessarily have to be codified, it is worth bearing in mind that DGS users and learners are exposed to and influenced by prevailing spoken language ideologies. This can be particularly observed with regard to notions of standard language ideology, which highlights the potential advantages of the existence of a variety that could potentially be taught to all L2 learners, and therefore appears to be highly prevalent in the DGS teaching and learning sector. The conjecture, however, that existence of a standard variety presupposes its codification, must be taken with caution insofar as in light of the non-existence of any conclusive large-scale empirically-based, lexico-statistic findings that might prove otherwise, it is simply impossible to know whether there might in fact exist a "standard variety" in the sense of supra-regional variety. The absence of a referenceable form that has been documented, described, codified and acknowledged as standard variety of DGS is often bemoaned in the context of DGS learning and teaching, which is a growing domain, both in relation to L1 teaching and learning within primary and secondary deaf education ${ }^{1}$ as well as in terms of L2 acquisition in the private lifelong learning sector

\footnotetext{
${ }^{1}$ This, however, is still not everyday practice at all schools for the Deaf.
} 
The above-mentioned factors constitute a field of tension insofar as (second) language teaching more often than not is geared towards transmitting standard varieties, which have been identified in reference to linguistic landscapes that are naturally defined by variation across all levels of the multidimensional Varietätenraum (i. e. variation space, Dittmar 1997). Thus, a growing domain of formal DGS teaching and learning will increasingly highlight the challenge between much observable variation on the one hand, and the absence of a codified standard on the other.

\section{$4 \quad$ On the social situation of DGS}

There are also a number of social factors that have had a bearing on the current status of DGS and that therefore, need to be considered when dealing with the question of what is standard in DGS. These include social changes in the perception and status of DGS as a genuine language, prevalent language ideologies, as well as the fact that new technologies facilitate new texts and genres which in turn call for new theoretical conceptualisations.

In Germany, up until the 1980s, typical Deaf signing was frequently referred to as plaudern ("chatting") (Hansen/Heßmann 2013). This label indicates that the visual-spatial mode of communication was not seen as on a par with spoken interaction, especially in terms of its potential to facilitate communication beyond informal chit-chat. There are various reasons for such misunderstanding. On the one hand this perception was a remnant of the historically grown ideology of the prominence of the spoken word, which has shaped Western/European epistemologies of language since the enlightenment period. As discussed by Baynton (1993: 107), this did not leave any room for the appreciation of apparently "monkey-like grimaces and antics" as a means of respectable human interaction. On the other hand, up until the middle of the 20th century, linguistic scholarship as wider academic discipline simply had not yet fully appreciated the fact that human languages might be expressed in a modality other than speaking and writing. Once sign language research has taken off with William C. Stokoe's seminal work on the structure of American Sign Language (Stokoe 1960), however, the overall situation changed so that nowadays, the exploration of visual spatial languages is of interest to scholars in various disciplines beyond (socio)linguistics (e. g. in computer sciences).

As a consequence of an increased academic interest in sign languages, the appreciation of DGS as a genuine language has undergone quite significant developments within the signing community. In terms of linguistic structure, up until the 1980s "proper" signing in more formal settings (e. g. the AGM of local Deaf Club) clearly resembled the visual-spatial representation of spoken language (Lautsprachbegleitendes Gebärden, $L B G$ ). Over the past three decades there has been a significant change in the perception of signed interaction, which also translates into the wider understanding of what acceptable - and authentic - DGS looks like. Whilst signed German is still employed as one communication code alongside others, it is no longer perceived as the embodiment of the most prestigious form of signing. DGS along with its unique linguistic structure, is nowadays not only much more confidently used within and without the community but on a social level it is indexical of belonging to the DGScommunity (Jaeger/Heßmann 2016). 
Finally, opportunities and possibilities associated with new communication technology not only facilitate the mergence of new forms of language but also open up new approaches of thinking about these. Specifically, state-of-the-art technological solutions of sign language data storage and distribution facilitate the emergence of new text forms, registers and arguably, normative varieties. Sign language interaction no longer relies on face-to-face interaction, signed texts can be recorded, stored, edited, and easily distributed. This has led some scholars to propose that the camera will have a similar effect on sign languages as the printing press had on spoken languages (Krentz 2006). Whilst such an effect remains to be empirically verified, new emerging text genres in German Sign Language, characterised by displaying key features of both face-to-face interaction and more distant texts, have been analysed and discussed (Hansen/Heßmann 2013).

Having offered a brief sketch of the linguistic and social situation of DGS, the remainder of this article will review the model proposed by Ammon (2003) and explore in some more detail which social forces might be relevant when it comes to determining what is standard in DGS.

\section{On social forces that might determine what is standard in a language (Am- mon 2003)}

There are quite a number of models that have been proposed to account for the development and implementation of standard norms (incl. Haugen 1983; Cooper 1989 etc.). Notably, these models have in common that they tend to focus on language planning aspects in relation to spoken languages, which have a written form and which also have (at least) one written codex. In other words, these languages in question are not only scripturally encoded but users of these languages can refer to a - however derived and encoded - body of lexical items and grammatical structures that are recognised as "standard". Furthermore, these languages in question tend to consider the development of standard norms from a retrospect point of view.

As a case in point, let me offer a brief sketch of Ammon's Model of the Social Power Field (2003) in which the author suggests that normative language varieties can thrive in contexts, where certain "social forces" are at work.

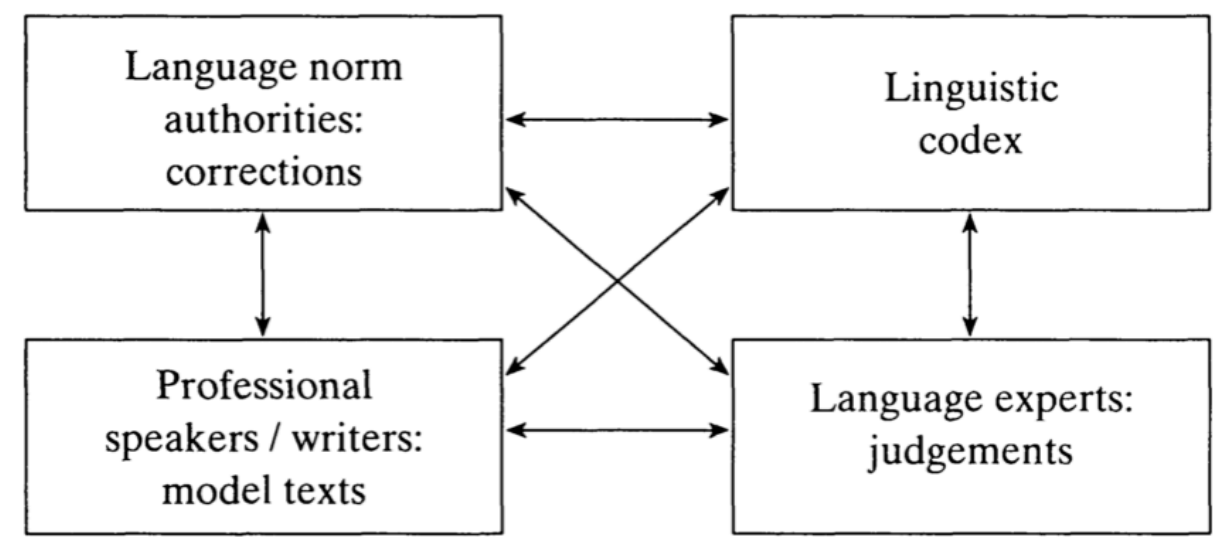

Figure 1: Model of the four social forces that determine what is standard in a language (Ammon 2003: 2) 
To begin with, there are "model speakers and model writers" whose language use in the public domain is attributed a certain prestige and therefore, considered by the wider audience as exemplary. Individuals associated with this category are often "member[s] of the intellectual elite or even, more specifically, [...] professional speaker[s] or writer[s]" (Ammon 2003: 2).

Alongside these speakers whose public language output is often equated with the production of model texts, there are "language norm authorities", i. e. individuals who use their power to correct others' language behaviour, both written and spoken. According to Ammon (2003), in the widest sense virtually anyone who wishes to correct others in terms of their linguistic output, can function as language norm authority. However, language norm authorities in a narrower sense are such individuals who - by virtue of their profession - hold the power not only to correct other peoples' language behaviour, but to sanction any deviances from the (codified) norm. Individuals such as "school teachers, or editors or copy-readers of publishers" (ibid.: 3) are seen as prototypical examples of this particular social force.

The "linguistic codex, in which the result of codification is published" (ibid.: 4, italics original) represents yet another social force in the proposed model, as it forms the basis on which language norm authorities are entitled to "correct the language behaviour of their norm subjects in line with the codex" (ibid.: 5). In order to exemplify the status as linguistic codex rather than mere linguistic description, the given entity in question (e.g. dictionary) has to be recognised and acknowledged as such. However, exactly how any collection of linguistic description can achieve (or be awarded) the status of a codex, remains unclear.

Finally, Ammon refers to "language experts" (ibid.: 6) who "are in a position where their criticism of the language codex is taken seriously" (ibid.: 6). By virtue of their professional and social status the individuals in question cannot only criticize and actively influence the recognised linguistic codex, but are often approached in cases where the codex is not perceived as final authority in cases of linguistic disputes.

Whilst the concept of what is standard has been extensively addressed in relation to spoken languages, overall there is still comparatively limited research in this area in relation to sign languages. It is reasonable to expect that there are merits in drawing on explanatory models from the wider sociolinguistic domain, e. g. in the sense that certain extra-linguistic factors which are considered relevant in the emergence and distribution of what is standard in spoken languages, can also be identified in sign language communities. Thus, referring to the above outlined model of the social power field, in the following section I will examine who or what might represent model speakers and model texts, language norm authorities, language codices and language experts in relation to DGS and discuss, to what extent Ammon's model offers a useful approach to identify social powers at play when it comes to determining what is standard in DGS.

\section{On social forces that might determine what is standard in DGS}

\subsection{Model DGS-texts and model signers}

At this moment in time it is rather unclear as to what constitutes model DGS texts and who might be considered model signers in the DGS-community. Since modern technology facilitates encoding and transmitting of sign language data via visual media (TV, Internet etc.) over

ISSN 1615-3014 
the past decade there has been a large increase in the sheer volume of DGS data that are supra-regionally transmitted. These include television broadcasts and Internet-based chat-shows, for example, which are aimed at the German sign language community and negotiated via DGS (cf. "Sehen statt Hören", "Fingerzeig", respectively), as well as official DGS translations of legal texts (e.g. the UN-Convention on the Rights of Persons with Disabilities (cf. www.bmas.de [09.01.2017])) and news broadcasts (cf. Phoenix, MDR Mediathek), which are interpreted in DGS. Numerous grass-root contributions on social media, such as Facebook and YouTube are also freely accessible.

To date, there is little evidence to suggest that any of the contexts or text genres referred to above, are perceived within the DGS community as in any form particularly prone to exhibiting model language. At first sight, this is interesting bearing in mind that in spoken language communities, language performance in news broadcasts, for example, is generally associated with a certain level of prestige and hence often also perceived as exemplary. Considering, however, that news on television are usually translated by hearing sign language interpreters (i. e. L2 signers), makes the finding rather less surprising. In contrast first insights from our on-going research suggest that deaf sign language users hold much admiration of individual signers who are e.g. well known for their skilled performance of poetic texts. Outside of the creative domain, however, there is limited evidence to suggest that language performance of particular individual signers is specifically perceived and/or consistently referred to as in any form representing exemplary DGS. Whilst it may be reasonable to expect that admiration of certain esteemed signers' language performance might translate into individuals' sign language practice, such correlation is yet to be confirmed. Likewise, whether or not perceived as such, in any case it remains to be examined, to what extent sign language interpreters, especially when operating in such publically exposed positions, factually operate as language models in the sense that that their language performance impacts language practice within the signing community.

\subsection{Language norm authorities}

DGS has only been legally recognised in 2001, and merely in the context of the Disability Discrimination Act (BGG §9). This means that, although in terms of its linguistic complexity and communicative efficiency DGS represents a fully fletched natural language, its legal status predominantly regulates interpreter provision for deaf individuals in various administrative and educational contexts. The language as such is neither legally protected nor acknowledged on a par with other minority languages in Germany like Sorbian, Danish and Saterland Frisian.

Despite an increasing awareness of the fact that access to DGS is crucial to deaf children's academic success, DGS is not yet genuinely included in the primary and secondary teaching sector, neither in the general, nor in the special education domain. In the context of language norm authorities, Ammon (2003) refers to the role of the Duden (a private publishing house) and the union of Austrian teachers (Österreichischer Gymnasiallehrerverband). According to the author, due to their status in the state-governed educational domain, both organs play a key role in establishing and promoting what is standard in German. Since DGS teaching and learning has not yet really been welcomed under its auspices, there is at current no real gov- 
ernmental interest in language related matters concerning DGS and, as a consequence, not yet any governmentally sanctioned body that has - in whichever form - an authoritative say on structural and functional aspects of DGS.

One might like to put forward that the existence of language norm authorities does not necessarily have to rely on state intervention but that such institution (however defined) could potentially evolve from below, i. e. the language user base. Although since the 1980s there are various institutions throughout Germany, which are actively engaged in matters of researching and teaching DGS, there is as yet no institutionalised language norm authority, which is endorsed by the DGS community in the wider sense to have authoritative say on DGS-related matters.

Ammon (2003) suggests that teachers embody language norm authorities. At first sight, this might hold true for DGS teachers, as qua their pedagogical practice they establish and convey linguistic standards. Bearing in mind, as pointed out above, that linguistic standards conveyed in DGS classes might not necessarily be the same as 'what is standard' in DGS, it is difficult to say what teachers' corrections might really aim at. On closer inspection, it becomes clear that the notion of DGS teachers personifying language norm authorities might be somewhat problematic, or, at the very least, not fully comparable to the situation of spoken German. Deaf sign language teachers are predominantly working in the foreign language domain as in most cases, deaf sign language teachers are educating hearing DGS learners. This is in some way comparable to German teachers in the DaF-Domain (Deutsch als Fremdsprache, German as a foreign language) rather than DaE-Domain (Deutsch als Erstsprache, German as first language). ${ }^{2}$ Oftentimes target groups are prospective sign language interpreters whose job it is to negotiate meaning between sign language users and non-signing individuals.

One of the challenges with which DGS teachers are regularly faced, is the non-existence of a linguistic codex of DGS, which is recognised as representing what is standard in DGS.

\subsection{Linguistic codex}

There are several DGS-lexicons and teaching and learning materials available (e.g. Metzger et al. 2006) which are used both in institution-based formal sign language teaching environments as well as in home-based teach-yourself settings. None of the resources available to date, however, can hold any substantiated claim to encoding or representing an authoritative linguistic codex of DGS. The first issue that immediately comes to mind in this context is the question to what extent it is at all possible to develop a linguistic codex of a language that is essentially devoid of a written form. Although it is possible and current practice to scripturally encode visual-spatial languages in academic research contexts and various educational settings, deaf people in Germany will usually revert to written German when it comes to written information exchange on a day-to-day basis. Widespread literacy in German simply means that there is an easily accessible alternative to writing DGS.

\footnotetext{
2 The teaching of DGS as a regular subject is still underrepresented in the Deaf education landscape and by no means, every day practice at schools for the deaf. In fact, DGS is included in the core curriculum only at schools for the deaf in Berlin, Brandenburg, Hamburg and Bavaria (Hennies 2013). In the context of these schools DGS teachers act as norm authorities in the sense that the actively assess, correct and broaden their students' sign language skills. Given that the majority of deaf children are born into hearing, and often non-signing, families, most of the pupils will be L2 learner, too.
} 

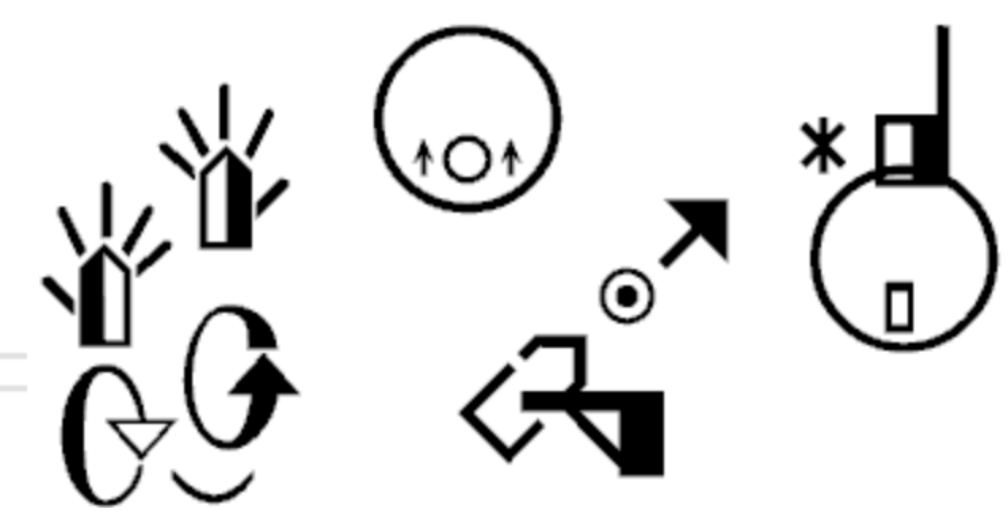

Figure 2: Example of Signwriting (Gebärdenschrift) (www.gebaerdenschrift.de [09.01.2017])

Considering modern communication technologies, which facilitate recording, editing, distribution and storage of visual-spatial language data, means that communicative practices are currently changing in that signed data are increasingly transferred across spatial boundaries. This can be observed both in personal, one-to-one interaction via live video messaging (e. g. www.glide.me [09.01.2017]), as well as in one-to-many settings, e. g. by posting information encoded in video clips on social network platforms such as Facebook. Whilst it has been proposed that an uptake of sign language data transfer across spatial and temporal boundaries (i.e. participants no longer have to be present at the same location at the same time) will contribute to the standardisation of sign languages (Sutton-Spence/Woll 1999), this still remains to be empirically verified.

The generally unspoken but evidently widespread assumption that a linguistic codex must be expressed in the written rather than spoken or signed modality first and foremost points to the prevailing ideology of the alleged supremacy of the written language. This can be traced in many discussions on social forces that determine what is standard in a language, but it is also a notion that quickly turns into a cul-de-sac when it comes to visual-spatial languages. Thus, notwithstanding the fact that the (non-)existence of a written code as we know it is likely to surface in any discussion on what is standard in a language, the conceptualisation of what a given language codex must - or can - look like, also has to re-think notions of modality. One discourse where this line of thinking is overtly addressed in relation to spoken languages is the notion of "spoken standard" ("Standardsprachlichkeit"), which has recently gained some momentum in relation to spoken German (e.g. Hagemann et al. 2013; Schneider 2011; Klein 2013). Whilst Schneider considers structural aspects of what might be categorised as spoken standard German, Maitz/Elspaß (2013) suggest that, in many respects, discussions surrounding its existence and desirability is predominantly informed by prevailing, culturespecific language ideologies (cf. Germany vs. Norway).

There are at current attempts to develop a corpus-based DGS dictionary in the context of the Hamburg DGS Corpus Project (http://www.sign-lang.uni-hamburg.de/dgs-korpus [09.01.2017]). Based on sign language data from research sites across Germany, the outcome is expected to result in a dictionary that reflects DGS as it is used by native signers. Feedback strategies are put into place in order to cross-check with, and ground the data in, grass-root knowledge and assessments of acceptability. The publication of the dictionary is expected in 2023 but at this moment in time, notwithstanding the importance of this project on numerous social and scholarly levels, it is difficult to foresee if the result will gain recognition as lin- 
guistic codex. Not least because it is unclear who or which are the relevant language norm authorities that will endorse such a status.

\subsection{Language experts}

Finally, I wish to draw some attention to what Ammon refers to as language experts. At first sight, both DGS-teachers and DGS- researchers are regularly approached and called upon when it comes to generating expert opinions on sign language related questions. To date, the majority of sign language experts are hearing linguists, many of them have cultivated an interest in sign linguistics in the context of their academic careers. Whilst these individuals are happy to volunteer their insights and expert knowledge in DGS-related matters, it can be observed that such knowledge distribution still predominantly takes place in academic settings, which, for various reasons, are mostly inaccessible to grass-roots Deaf sign language users. Outside the academic domain hearing professionals often hesitate to overtly assume DGS expert status and thus, power is easily handed over - at least on the surface level - to the "real" experts on DGS, i. e. Deaf CODAs, that is, Children of Deaf Adults.

The status of deaf CODAs as language experts is widely recognised within the Deaf community. Due to the lack of inter-generational transmission, the majority of deaf sign language users in signing communities in the Western world have been traditionally referred to as nonnative signers or L2-speakers. ${ }^{3}$ Only a small fraction of the overall community can be argued to belong to the core language community in the sense that they are born into Deaf signing families where they acquire sign language as their first language. Compared to spoken languages in the Western world, where children usually first acquire the language of their parents or carers, this situation is rather unique to sign language communities. There are many communities where "new speakers", i. e. language users who have acquired the target language beyond childhood and outside their home (O'Rourke et al 2015), present a significant part of the overall language community. However, the situation in Deaf communities is somewhat different in that many Deaf children, due to their physical inability to fully access spoken language, experience a somewhat delayed first language acquisition.

On account of numerous observations as well as interviews with deaf DGS-users (cf. Eichmann 2013) it can be argued that the native speaker bias is deeply ingrained in the DGS community. This can be observed in situations when deaf participants are confronted by linguistic professionals with specific questions, e. g. regarding grammatical or lexical aspects of DGS. Very proficient signers who have been exposed to and who have used DGS for many years (often from Kindergarten age onwards) will freely articulate their own understanding of the subject matter, e. g. by showing their sign variant for the concept in question (cf. Eichmann 2013). However, having communicated their view, the same individuals will oftentimes be quick to refer the enquirer to another person for a second opinion. This other person usually being a deaf CODA, i. e. a 'native' signer from Deaf descend, and thus, by virtue of their linguistic biography, apparently understood to hold an even more valid linguistic authority on the subject matter in hand.

\footnotetext{
${ }^{3}$ Although the term "speaker" is usually associated with spoken language users, it increasingly finds application in the sign language literature in that it is used to refer to individual language users irrespective of the modality of the target language.
} 
Interestingly, (sociolinguistic) research practice actively contributes to the constant reenforcement of such dynamics. Considering sign language research in terms of participant selection criteria applied, it can be noticed that it oftentimes seems desirable to collect language data from participants who are considered as close to the core language community as possible. This observation can be made both in studies examining structural as well as in more sociolinguistically oriented research. First choice candidates appear to be those participants who have acquired sign language at home from their deaf parents. Given the restrictedness of the target group, participants who have acquired sign language skills in their early childhood years (usually before reaching school entry age) will also often be included in the study. This practice of participant selection, along with the lack of acknowledgment of the native speaker bias that is inherent to it, suggests that only 5 to 10 per cent of an entire language community constitutes "authentic informants". Whilst scholars might have theoretically informed reasons to limit their selection criteria to only a small subsection of the overall language community, only few authors acknowledge and overtly address the fact that they subscribe to the native speaker bias including its underlying ideological connotations. One of these being Hill (2015: 203) who argues that researchers must "accept that variety of communication and of language experience has become the norm for deaf signers and that sociolinguistic studies of signers whose sign language exposure was delayed are highly encouraged, for the sake of capturing the linguistic and cultural realities".

\section{$7 \quad$ Discussion and concluding remarks}

Ammon never promised that his model would be applicable to all languages, but the author did express his expectation (hope?) that transferability might lie within its simplicity. Throughout the paper it was shown that Ammon's model is not immediately transferable to the social and linguistic situation of visual-spatial languages as it presupposes a number of factors, which might not represent identical forces in every language community.

First of all, Ammon's model is inherently modality bound in the sense that it presupposes the existence of a written language, which can encode what is standard in a language, which can serve as a reference point when it comes to challenging and/or promoting what is standard and in relation to which personified social forces (language experts and professional writers/speakers) can frame their arguments. The absence of a writing system that is used within the DGS community in a comparable way to written German in the German speaking countries, does not necessarily mean that scriptural encoding does not exist as a relevant social force in Deaf communities. It does mean, however, that we must re-think prevailing conceptualisations of scripturality by taking on board issues of modality.

Secondly, it was shown that there are multi-layered social forces and dynamics at work in the DGS community, such as the native signer bias as well as the fact that the language community largely consists of L2 signers, which might not comfortably fit any of the social forces depicted by Ammon (2003), which may typically be found in spoken language communities that regularly operate within and cherish scripturality.

In developing explanatory models, we might never be able to fully account for all languages, but acknowledging the modal boundaries we are operating within, throughout the paper it was shown that when it comes to sociolinguistic theorising, modality matters nonetheless. This 
does not mean that all sociolinguistic models necessarily have to be modality independent. However, it is timely to acknowledge that to date much sociolinguistic theorising is intrinsically biased towards and based on our understanding of social forces at play, and linguistic features evident in relation to spoken and written languages and their respective host communities. Considering the social and linguistic situation in other languages, such as DGS, broadening one's theoretical horizon towards visual-spatial languages, and identifying social forces that might be relevant to those settings, facilitates a more holistic understanding of language as a human and social faculty.

\section{References}

Ammon, Ulrich (2003): "On the Social Forces that Determine what is Standard in a Language". Sociolinguistica 17: 1-10.

Ammon, Ulrich (2005): „Standard und Variation: Norm, Autorität, Legitimation“. In: Eichinger, Ludwig/Kallmeyer Werner (eds.): Standardvariation. Wie viel Variation verträgt die deutsche Sprache? Berlin, de Gruyter: 28-40.

Bayley, Robert/Lucas, Ceil (2007): Sociolinguistic Variation: Theories, Methods, and Applications. Cambridge: Cambridge University Press.

Baynton, Douglas (1993): "Savages and Deaf-Mutes. Evolutionary Theory and the Campaign Against Sign Language in the Nineteenth Century". In: Cleve, John Vickrey Van (ed.): Deaf History Unveiled: Interpretations from the New Scholarship. Washington, D. C., Gallaudet University Press: 92-112.

Cooper, Robert (1989): Language Planning and Social Change. Cambridge: Cambridge University Press.

Dittmar, Norbert (1997): Grundlagen der Soziolinguistik - Ein Arbeitsbuch mit Aufgaben. Tübingen: Niemeyer.

Eichmann, Hanna (2009): "Planning sign languages: promoting hearing hegemony? Conceptualizing sign language standardization”. Current Issues in Language Planning 10/3: 293307.

Eichmann, Hanna (2013): “Hands off our language!” Deaf sign language teachers' perspctives on sign language standardization. Aachen: Shaker.

Eichmann, Hanna/Rosenstock, Rachel (2014): "Regional Variation in German Sign Language: The Role of Schools (Re-)Visited". Sign Language Studies 14/2: 175-202.

Hagemann, Jörg/Klein, Wolf Peter/Staffeldt, Sven (2013): „Pragmatischer Standard - Eine Annäherung“". In: Hagemann, Jörg/Klein, Wolf Peter/Staffeldt, Sven (eds.): Pragmatischer Standard. Tübingen, Stauffenburg: 1-13.

Hansen, Martje/Heßmann, Jens (2013): „Register und Textsorten in der Deutschen Gebärdensprache: Eine korpusbasierte Annäherung“. Zeitschrift für angewandte Linguistik 58/1: 133-165.

Haugen, Einar (1983): "The Implementation of Corpus Planning. Theory and Practice". In: Cobarrubias, Juan/Fishman, Joshua (eds.): Progress in Language Planning. International Perspectives. Berlin, de Gruyter: 269-291.

Hennies, Johannes (2013): Kommentierte Literaturliste für das Unterrichtsfach „Deutsche Gebärdensprache (DGS) “. Ludwigsfelde-Struveshof: Landesinstitut für Schule und Medien Berlin-Brandenburg (LISUM). (=Unterrichtsentwicklung). 
Hill, Joseph (2015): "Data collection in sociolinguistics". In: Orfanidou, Eleni/Woll, Bencie/Morgan, Gary (eds.): Research Methods in Sign Language Studies: A Practical Guide. Oxford, Blackwell: 193-205.

Hillenmeyer, Margit/Tilmann, Savina (2012): „Soziolinguistik: Variation in der DGS”. In: Eichmann, Hanna/Hansen, Martje/Heßmann, Jens (eds.): Handbuch Deutsche Gebärdensprache. Sprachwissenschaftliche und anwendungsbezogene Perspektiven. Seedorf, Signum: 245-270.

Holmes, Janet (2013): An Introduction to Sociolinguistics. 4. Auflage. New York: Taylor \& Francis.

Jaeger, Hanna/Heßmann, Jens (2016): „Mikrovariation in Gebärdensprachen“. In: Domahs, Ulrike/Primus, Beatrice (eds.): Handbuch Laut, Gebärde, Buchstabe. Berlin: de Gruyter: 321-334.

Klein, Wolf Peter (2013): „Warum brauchen wir einen klaren Begriff von Standardsprachlichkeit und wie könnte er gefasst werden?“ In: Hagemann, Jörg/Klein, Wolf Peter/Staffeldt, Sven (eds.): Pragmatischer Standard. Tübingen, Stauffenburg: 15-34.

Krentz, Christopher (2006): "The camera as printing press". In: Bauman, Dirksen/Nelson, Jennifer/Rose, Heidi (eds.): Signing the Body Poetic: Essays on American Sign Language Literature. Berkeley, University of California Press: 51-70.

Langer, Gabriele (2012): "A Colorful First Glance at Data on Regional Variation Extracted from the DGS-Corpus: With a Focus on Procedures". In: 5th Workshop on the Representation and Processing of Sign Languages: Interactions between Corpus and Lexicon Language Resources and Evaluation Conference (LREC). Istanbul: 101-108.

Lucas, Ceil et al. (2002): "Location Variation in American Sign Language". Sign Language Studies 2/4: 407-440.

Lucas, Ceil/Bayley, Robert (2005): "Variation in ASL: The Role of Grammatical Function". Sign Language Studies 6/1: 38-75.

Maitz, Péter/Elspaß, Stephan (2013): „Zur Ideologie des ,Gesprochenen Standarddeutsch““. In: Hagemann, Jörg/Klein, Wolf Peter/Staffeldt, Sven (eds.): Pragmatischer Standard. Tübingen, Stauffenburg: $35-48$.

Metzger, Christiane/Schulmeister, Rolf/Zienert, Heiko (2006): Die Firma. Deutsche Gebärdensprache Do It Yourself. Multimedia DVD-ROM, 2. überarbeitete Auflage. Seedorf: Signum.

O'Rourke, Bernadette/Pujolar, Joan/Ramallo, Fernando (2015): "New speakers of minority languages: the challenging opportunity". International Journal of the Sociology of Language 231: 1-20.

Schembri, Adam et al. (2009): "Phonological variation and change in Australian and New Zealand Sign Languages: The location variable". In: Language Variation and Change 21/2: 193-231.

Schneider, Jan Georg (2011): „Hat die gesprochene Sprache eine eigene Grammatik? Grundsätzliche Überlegungen zum Status gesprochensprachlicher Konstruktionen und zur Kategorie ,gesprochenes Standarddeutsch““. Zeitschrift fur Germanistische Linguistik 39/2: 165-187.

Siple, Patricia (1978): Understanding Language through Sign Language Research, New York: Academic Press. 
Stokoe, William (1960): Sign Language Structure: An Outline of the Visual Communication Systems of the American Deaf. Silver Spring, MD: Linstok. (= Studies in linguistics. Occasional papers 8).

Sutton-Spence, Rachel/Woll, Bencie (1999): The Linguistics of British Sign Language. Cambridge: Cambridge University Press.

Wardhaugh, Roland (2011): An introduction to sociolinguistics, Oxford: Wiley-Blackwell.

Woll, Bencie/Sutton-Spence, Rachel (2004): Sign Language/Zeichensprache. In: Ammon, Ulrich et al. (eds.): Sociolinguistics/Soziolinguistik. Berlin: de Gruyter: 677-683. 